\title{
Multi-Stakeholder Innovation in Smart City Discourse: Quadruple Helix Thinking in the Age of "Platforms"
}

\author{
Koen Borghys ${ }^{1 *}$, Shenja van der Graaf ${ }^{1}$, Nils Walravens ${ }^{1}$ and Mathias Van Compernolle ${ }^{2}$ \\ ${ }^{1}$ imec-SMIT, Vrije Universiteit Brussel, Brussels, Belgium, ${ }^{2}$ imec-MICT, Universiteit Gent, Ghent, Belgium
}

\section{OPEN ACCESS}

Edited by:

James Evans,

University of Manchester,

United Kingdom

Reviewed by:

Maurizio Giacomo Catulli,

University of Hertfordshire,

United Kingdom

Robert Cowley,

King's College London,

United Kingdom

*Correspondence:

Koen Borghys

koen.borghys@imec.be

Specialty section:

This article was submitted to

Governance and Cities,

a section of the journal

Frontiers in Sustainable Cities

Received: 29 November 2019

Accepted: 24 February 2020

Published: 20 March 2020

Citation:

Borghys $K$, van der Graaf $S$ Walravens $N$ and Van Compernolle $M$ (2020) Multi-Stakeholder Innovation in Smart City Discourse: Quadruple Helix

Thinking in the Age of "Platforms".

Front. Sustain. Cities 2:5.

doi: $10.3389 /$ frsc. 2020.00005
The predominant rhetoric in smart city debates puts the emphasis on collaboration. Conceptualizing, designing, implementing, validating, and evaluating solutions to urban challenges with all relevant stakeholders around the table are perceived as the optimal modus operandi in these perspectives. But how does this vision relate to current practices in cities? This paper deals with the observed trend toward more multi-stakeholder collaboration and the resulting complex value networks these stakeholders need to navigate. This is exemplified in what has been called the "platformization" of the urban space by "urban service platforms" (e.g., Uber, AirBnB) as well as in so-called "quadruple helix" approaches to urban innovation. Particularly for (local) government, finding a role in these complex networks has proven challenging. This paper explores the main challenges concerning multi-stakeholder innovation and opportunities related to this topic.

Keywords: quadruple helix, smart city, governance, multi-stakeholder, platform urbanism

\section{INTRODUCTION}

What do the quadruple helix innovation model and platform urbanism have in common? They are conceptual forms of the current smart city rhetoric associated with an innovation-driven, user-oriented, and multi-stakeholder take on governance within the urban context. While a concise definition of what the smart city entails may not be easily distilled in the literature, it can be said to point to an intensification of the use of information and communication technologies (ICT) and data by local authorities, and in its execution, seeking closer collaboration with other stakeholders, in particular, citizens (Anthopoulos et al., 2016; Walravens, 2016). One concept associated with the operationalization of this process is what has been termed the quadruple helix (Arnkil et al., 2010; Cavallini et al., 2016; Borkowska and Osborne, 2018). It points to the logic of a cooperation model associated with the design and development of innovative city services, which complements the public sector with companies, academia, and citizens. In practice, however, a high level of involvement by all partners seems rarely to be the case (Borkowska and Osborne, 2018). Simultaneously, a trend can be detected toward a so-called "platformization" of the creation and delivery of services and products in the city and the public domain, developed and offered by (typically) private players [e.g., ride-hailing (Uber), journey planning (CityMapper), property rental (AirBnB), and electric scooter sharing (Bird)] that are rarely co-designed with cities, or only leave little space for post factum collaboration [e.g., Waze (Alphabet/Google)], or, more problematically, warrant regulation. Associated with the "platform force majeure" are so-called 
platform companies like Facebook and Google that have positioned themselves in the (service) marketplace cutting across sectors, genres, and so forth, thereby highlighting a reconfiguration of production, consumption, distribution, and monetization of (cultural) goods and services (Nieborg and Poell, 2018). Understanding the dynamics and influence of the emergent "platform logic" on society has become an important task at hand. Many terms, concepts, and models like "platform society" (van Dijck et al., 2018), "platform capitalism” (Srnicek, 2017), and "platform governance" (Gillespie, 2010, 2018) have appeared purportedly pointing to the penetration of digital platforms into the heart of society, disrupting markets and labor relations (the "gig-economy"), transforming social and civic practices, as well as affecting democratic processes. In the context of the city, "platform urbanism" has been deployed to describe the dynamics between "community and commerce," which reveals a complex platform-based ecosystem encompassing private and public organizations and citizens (Barns, 2016; van der Graaf and Ballon, 2019). This can be illustrated by regulation impacting on this multi-stakeholder ecosystem such as in Amsterdam, where since 1 January 2019 AirBnB properties cannot be rented out in their entirety for more than 30 days in a year (Sine Nomine, 2018).

A multi-stakeholder (platform-based) ecosystem perspective on urban innovation frameworks has gained traction in public and private spheres and is considered to be benevolent for society. Concurrently, it calls for a critical assessment of public value in urban innovation processes and the role and responsibilities that local governments can play, both materially and institutionally (Gillespie, 2018). This is precisely the objective of this paper: it aims to explore the role of cities in this intertwined trend of "quadruple helix thinking" in the "platform" era that seem to underpin the current smart city rhetoric. While the quadruple helix concept continues to be promoted in the smart city discourse, the examples of impactful cases that positively influence services provided to citizens are few and far between (Cavallini et al., 2016). At the same time, platform(-based) companies are succeeding in creating services that add value for citizens, but operate in an uncertain regulatory state, with questions related to privacy, ethical working conditions, use of and access to data, the commodification of the public space and so on popping up. Arguably, the platform mantra typically centerstages private entities and the quadruple helix public onesyet both are indicative of local authorities (and governments in general) struggling with the roles, if any, they can take up in such complex multi-stakeholder ecosystems (van der Graaf, 2018a).

The empirical work for this paper has been carried out in the framework of the Smart Flanders program, which was initiated by the Flemish Government (Belgium) in early 2017. The goal of the 3-year program was to support the 13 so-called center cities in Flanders (by and large the biggest cities, with the largest counting over 500,000 inhabitants and the smallest around 40,000) and a representation of the Flemish Community in the Brussels Region (referred to as the $13+1$ ), with defining and implementing common (open) data policies. The results of the program give insight into the motivations and concerns of cities related to navigating the Quadruple Helix.

In the next section, key concepts related to the quadruple helix in the context of the "platform age" are explored. The conceptualization of "platforms" and how they became more and more relevant to the urban space is discussed, as well as the origins and current operationalization of the quadruple helix principle. This is followed by a discussion of the findings from the program described above, which show how local governments currently interpret and apply the quadruple helix concept and where challenges remain. The concluding section discusses how the concepts of platforms and quadruple helix are linked and how cities may deal with some of the challenges associated with them in the future.

\section{PARTICIPATION AND INNOVATION IN PERSPECTIVE}

With the advent of "the platform," arguably, extending from platform companies' boundaries into society at large, critical scholarship is urgently seeking to grasp what is going on and what it means (van Dijck et al., 2019). The changes associated with the platform are profound as their "disruptive" activities are said to be entirely contingent on, for example, geo-logistics as a business model (think Airbnb, Uber, Waze). Perhaps unsurprisingly, the growing theorization and body of empirical evidence that engages with "platforms," particularly in media studies and geography, tends to focus on (often, rigid) accounts of power that seem to downplay or exclude users (or, citizens) and the significance of the surroundings in everyday life (Kitchin et al., 2018; Parker and Van Alstyne, 2018). Furthermore, the role of data, associated with particularly the term "datafication"1, has taken center stage in these debates, thereby highlighting the intertwined streams of thought about participation and innovation (Couldry and Mejias, 2019; Livingstone, 2019).

The idea of participation is not new but gained momentum as evidence of the so-called "participatory turn" associated with the Web 2.0, offering users an easy-to-use creative infrastructure to actively engage in digital development practices ( $O$ 'Reilly, 2017). More specifically, facilitated and dynamically built in this platform logic, such user practices are indicative of rapidly evolving, yet, often subtle (interdependent), relationships of collaboration among users (such as citizens in their roles of inhabitants, visitors, tourists, property owners, etc.) but also with other stakeholders across public and private organizations, and platform boundaries underlying product or service development (van der Graaf, 2018b). Central to this is the concept of "multi-sided markets" where a platform enables interaction between distinct parties (Rochet and Tirole, 2003; Parker and Van Alstyne, 2018). Platforms and their providers mediate and coordinate between different stakeholders, which are the two (or multi-) sides of the market (Evans and Schmalensee, 2016).

\footnotetext{
${ }^{1}$ Datafication refers to sensing and the subsequent collecting of all kinds of data in machine-readable data formats (Janssen et al., 2017) or the transformation of social action into online quantified data, thus allowing for real-time tracking and predictive analysis (Mayer-Schönberger and Cukier, 2013).
} 
This, arguably, has become the dominant and common online organizational form for platform companies to describe their role in the market and their services toward their stakeholders including cities, associated with a strong neoliberal ethos underpinning all kinds of (meta)data appropriations (Plantin and Punathambekar, 2019).

Inviting users to participate, connect, and "co-create" has been indicative of a shift from a more closed production and innovation model to a more open, distributed and modular model. An intertwined stream of thought in this context is that of the "democratization of innovation" (von Hippel, 2005). Traditionally, innovation was seen as an inherently closed process with most operations running inside the boundaries of the company and research and development processes taking place in secretive in-house laboratories: knowledge and technologies were protected and kept safe from external influences (Schuurman et al., 2014). These exclusively closed modes of innovation have evolved in the last decades and new, open models of innovation have started to emerge (Chesbrough, 2006). Users and communities started to become an integral part of the global innovation ecology due to the gradual opening up of firms innovation processes and the new role of lead users and (technology) enthusiasts. This evolution is referred to as the "democratization of innovation" and proposes a "usercentric innovation" model in which "lead users" contribute to the performance of innovation systems (Carayannis and Campbell, 2009). This process became more and more facilitated by (software-based and often firm-provided) toolkits, which foster a modular approach to product and service development across firm boundaries. This emergent dynamic is said to essentially shift power relations marked by questions of value.

In the urban setting, this can be seen to be played out as a kind of emerging "platform urbanism." For example (social), traffic and navigation application, Waze (Waze Mobile/Google), offers a complex platform-based ecosystem encompassing private and public organizations and citizens manifesting (contested) dynamics in mobility practices occurring between commerce and community in the public space of the city (van der Graaf and Ballon, 2019).

In this view, user-centered platform-based innovation processes do not only offer great advantages for businesses, but they are also considered to be progressively interesting strategic models for public organizations (von Hippel, 2005). Currently, this is referred to in the smart city discourse by the so-called "quadruple helix innovation model," which considers citizens and "civil society" as a key element in the process of technological innovation (Anttiroiko, 2016). Originating from the so-called triple helix, the model is grounded on the idea that innovation is the outcome of an interactive process involving different "spheres" of actors ("helices") that intertwine and, in this way, generate an innovation system (Carayannis and Campbell, 2009) and each contribute according to their "established" or "institutional" function in society (Cavallini et al., 2016; Borkowska and Osborne, 2018). The underlying logic seems to hold that it is thanks to their relationships that actors are able to support a more impactful innovation process. It is this rationale that closely links platform models and the quadruple helix thinking. What the relationships between actors look like, how they are defined, or who contributes what and when, are however far less clear in either approach and will further guide the discussion in this paper.

Where the triple helix was structured around universityindustry-government relations (Etzkowitz and Leydesdorff, 2000), the quadruple helix included and considered the "citizen" or "civil society" as a key agent in the innovation process. In the context of smart city thinking, this translates to including citizens or communities that inhabit the smart city in product and (often, platform-based) service innovation and general decisionmaking processes and considering this involvement of citizens as key to building successful smart strategies (Calzada and Cowie, 2017). It is the human or rather social side of such intelligence that assumes that a heterogeneous group of people is able to provide smarter solutions than an individual expert; the idea that diversity trumps expertise. This frame of thinking connects the smart city discourse to inclusive, open, and user-driven innovations as critical elements of smart urban development (Anttiroiko, 2016).

The premise of making citizens co-creators of services and policies is said to enhance the innovative character and effectiveness of those services, and lead to new forms of government-to-citizen and citizen-to-government interactions (Linders, 2012). Although participation activities exist, in practice, it has proven challenging for governments to collaborate with citizens in such processes of innovation, in a sustainable way. Governments generally struggle with the complexity of the process and topics, with the time needed to invest in such processes, the diverging interests at play in complex value networks or with unclear goals of the interactions (Linders, 2012; Cavallini et al., 2016; Walravens, 2016).

Against this backdrop, the complex issue of the role and function of (local) governments in quadruple helix cooperation becomes apparent. This warrants the question what-if anythe role of governments is in the above-described multistakeholder ecosystems, and how this relates to the role of citizen participation and involvement in-increasingly, platform-based-innovation processes.

\section{THE QUADRUPLE HELIX IN PRACTICE \\ Methodology}

In order to establish a state of the art around some of these topics, first, a written survey was conducted with the cities in the Smart Flanders program (see above). This survey asked the participating cities how they define the smart city concept, whether and how they currently organize around it, how they spend resources on smart city projects, and how they think about technology and data. The survey also aimed to document whether any smart city policies were already in place and what these may entail. The representatives of the $13+1$ cities in the Smart Flanders steerco filled out this survey $(n=14)$, collecting information with colleagues from different departments whenever necessary.

This initial written survey was then complemented by a round of in-depth expert interviews with representatives of the $13+1$ cities. These semi-structured interviews (Schmidt, 2004; 
Rathbun, 2008) allowed us more insight into the motivations, concerns, and challenges raised by trying to establish a smart city strategy and what the role of the quadruple helix can be in this context. Where the survey had the aim of gathering basic information or documentation on potential strategies already in place, the interviews allowed expanding on this information in more detail. Fourteen interviews were held between April and October of 2017, with multiple representatives of the cities present (see below). This round was then repeated in the summer of 2019, to identify changes or evolutions in views.

The city representatives were asked questions related to four main topics: vision and strategy, management and organization, acquiring technology, and working with data. For each of these domains, the city representatives reflected on best and worst practices, what challenges and opportunities they see, how they evaluate interaction with other levels of government, with market players, what their role should be vis-à-vis innovation, procurement of innovative solutions, and so on.

The participants ranged from politicians, civil servants responsible for data management, ICT, geographical information systems, local economy, mobility, and so on. Representatives from the following cities were interviewed: Aalst; Antwerp; Bruges; Genk; Ghent; Hasselt; Kortrijk; Leuven; Mechelen; Ostend; Roeselare; Sint-Niklaas; Turnhout and the Flemish Community Commission in Brussels. When compared at the European level, these cities are relatively small in scale, with the largest counting over 500,000 inhabitants (Antwerp) and the smallest just over 40,000 (Turnhout). The 2017 interviews lasted between 2 and $4 \mathrm{~h}$ and the 2019 interviews between 1 and $2 \mathrm{~h}$, as reference could easily be made to the material from 2017. The interviews were transcribed and the data were coded and structured in tables, based on the topic at hand. The main results from these surveys are summarized in the following section, with a particular focus on experiences of quadruple helix practices.

\section{Findings}

Based on the insights gleaned from all this material, it is clear that the smart city rhetoric has put citizen participation and quadruple helix thinking on the agenda of the cities, influencing their view on collaboration, especially with regard to the role of technology in society or processes of innovation. All of the interviewed cities have some experience in collaborating in a quadruple helix ecosystem approach, usually within the context of projects (and as a result, mostly in an ad hoc manner). When asked when such an effort would be deemed successful, cities mostly point to the act of simultaneously getting representatives from all actors in the quadruple helix around the table to discuss a certain topic, e.g., in workshops, ideation sessions, project meetings, and so on. Most of the cities that arrived at this type of collaboration did this in the frame of a project that is funded by external resources, e.g., in an H2020, or Interreg project, funded by the European Commission.

When these cities are asked to operationalize quadruple helix collaboration, they mostly refer to living lab setups, structural and ad hoc meetings with different stakeholders, or triple helix projects. Although this approach has been touted as the best modus operandi in so-called smart city projects, in most cases, cities remain disillusioned with the results of their efforts. Very often, practical and budgetary concerns are the most important bottlenecks, together with limited knowledge of the oftentechnical topics, uncertainty on how to allocate budget to these initiatives, the goal of the collaboration being insufficiently clear, and so on. Particularly in Flanders, with relatively small cities, scale can be a hindrance, as some local governments feel such endeavors should be taken at the level of the Flemish regional government and not the local level. As a result, several city administrations have grown more skeptical of the concept and approach and some are abandoning it altogether. However, a more critical approach is potentially beneficial in this context, as quadruple helix collaboration is more likely to be sought out only when it is relevant to all involved stakeholders, increasing its potential impact. Examples of innovation setups described as quadruple helix efforts by the cities include the "Smart Zone" in Antwerp, where citizens and companies can experiment with innovative IoT solutions, supported by academic research in and in a real-life neighborhood of the city. Other cities like Hasselt and Roeselare regularly organize meetups around different topics (e.g., mobility, water, air quality, agriculture), inviting actors from the quadruple helix to brainstorm around innovative solutions, with the main aim of initiating new projects. The smart city vision text for the city of Sint-Niklaas was written with actors from the local quadruple helix over the course of a number of co-creation sessions and the city of Aalst experiments with innovative health and elderly care solutions in the Aging in Place living lab.

When discussing the roles cities see themselves taking up a quadruple helix constellation, it is interesting to note that, although they often facilitate or even initiate the collaboration, they would much prefer other actors to take up this coordinating role. This would allow cities to be perceived more as an equal participant in the quadruple helix, rather than the party enabling the collaboration. As a result, many cities are still experimenting with different approaches and methods to organizing, fostering, and sustaining these initiatives.

\section{Discussion}

An important explanation guiding these insights can be found in the way the quadruple helix is interpreted by cities and, as a consequence, the way it is implemented: whereas the concept is seen in the literature as a way to innovate together (see above), in its execution, it often boils down to several, recurring meetings with representatives from the four "helices" in the local ecosystem, with the goal of coming up with new project ideas, or as a forum to share challenges and concerns. In this light, the "quadruple helix" approach is mostly reduced to a means of gathering new project ideas, which can only be taken so far, especially if those projects fail to materialize. It has to be mentioned though that on several occasions, these types of structural meetings in Flemish cities (interestingly referred to as "platforms"-see below) have led to new innovation projects being acquired through subsidy channels, or to the successful collaborative creation of a smart city vision policy document in the case of one city. 
Perhaps unsurprisingly, as a result, cities prefer to work within the familiar, existing bilateral relationships or through a triple helix approach, rather than "forcing" themselves and other actors into quadruple helix constructs. This kind of behavior is in fact reinforced by local governments' tendency to be quite risk averse and having limited resources, whereas the innovation premise precludes taking risk. Furthermore, the practice of involving citizens in these processes has proven to be exceedingly challenging. Cities tend to have a lack of knowledge about (e.g., co-creation and engagement) methods as well as the capacity or resources to organize this. A clear, increased emphasis on citizen involvement can be detected, however, and which is even noticeable between 2017 and 2019: city administrations and policy makers are aware of the potential value of citizens' involvement in ideation, co-shaping of services, or even decisionmaking and are looking for optimal ways of organizing. Various existing techniques are deployed, such as focus groups, user tests, participating in monthly resident meetings, citizen consultations via surveys, hackathons, gathering data via citizen science, online citizen platforms, citizen advisory boards, and so forth. The current lack of a unified methodological approach and divergent operationalizations of the concept of "participation" in these cities is indicative of the present-day exploratory nature of (many of) these initiatives (see importance of role and expectation setting in Schütz et al., 2019).

Against this backdrop, cities are thus increasingly confronted with the practices of the "platform industry" as described at the onset. In those constellations, the government is very rarely involved in the innovation process of services or products itself, except in a post factum, regulatory (or, at times, usage) capacity. Where governments struggle to involve citizens in their quadruple helix approach-arguably, paralleling a platform model approach-these privately operated platforms do succeed in generating user involvement, be it by recharging e-scooters at night, renting out their apartments, or reporting accidents on their routes. Whether this type of "participation" is desirable is another debate, but it does illustrate the tension that arises when these approaches meet. There is the potential for complementarity and real collaborative innovation, but today, a number of factors, such as limited capacity, experience, and resources with government, prevent this.

\section{LOOKING FORWARD: PLATFORMS AND THE QUADRUPLE HELIX ON A COLLISION COURSE OR COMPLEMENTARY?}

Recent disruptive service offerings by platform companies and the ongoing debate related to smart cities have triggered (local) governments to consider their role in this ecosystem. The private interest behind some of these digital service platforms has propelled a very quick growth, often beyond the control of government (e.g., in the cases of AirBnB, Uber, Google). While it can be debated whether the government even should be involved in such platforms, some of the perceived negative effects (or, deliberate disruptions) as illustrated in this paper warrant some degree of government interest or involvement (e.g., through regulation).

Concurrently, governments are exploring their own role in the urban innovation ecosystem and in research and innovation projects and programs, with the goal of increasing effectiveness and efficiency of public service delivery. For cities, it is the perception that the quadruple helix model is the ideal way forward in enabling the involvement of all relevant stakeholders from the private, public, and academic sector, as well as citizens. Where platform operators have proven exceedingly successful in attracting citizens to create value on both (and multiple) sides of the platform, governments struggle particularly with this point, as well as their role in the quadruple helix. To this day, it is unclear what they can take away from multi-stakeholder platform models as such. Current interpretations and operationalizations of the concept are restricted to meetings or ad hoc project collaborations, yielding mostly limited success or results.

What these ongoing trends in urban innovation associated with both platformization and the quadruple helix point to is the need for a critical (self-)reflection on how local governments position themselves in such ecosystems. The finding that local governments do not always want to take up a coordinating role in a quadruple helix setting, but at the same time are expected to step up in a regulatory capacity when commercial platforms become dominant, is indicative of the complexity of their position. This is an ongoing process, where in the case of Flanders, the same group of 13 cities has developed a common view on the smart city concept, including a reflection on their role in an innovation system, stating: "The local government can take up different roles, depending on the projects and which stakeholders or technological solutions are involved: local government can initiate, facilitate, direct, stimulate, regulate, experiment, test, validate, implement... The local government performs this function to serve and protect the public interest" (Walravens et al., 2019, p. 4). Depending on the rationale behind the project or initiative, the stakeholders involved, the goals, pre-determined key performance indicators, and so forth, this role can change, but the key message is that the reflection needs to be actively made, and continuously evaluated. The need for this constant reflection in urban innovation is what ties platformization and quadruple helix thinking together.

The clear bottleneck then-identified by cities themselvesis a lack of (sustainable) resources, experience, and capacity to focus on these challenges. If governments are serious about innovative approaches to public service delivery and want to position themselves vis-à-vis unbridled private initiatives by platform companies in the public space, investing in these pain points will be of critical importance. Ongoing and future work should focus on developing methods that fit existing government processes and tools and methodologies that support capacity building in these areas.

\section{DATA AVAILABILITY STATEMENT}

The data used for this study are available (in Dutch) upon request to the corresponding author. 


\section{AUTHOR CONTRIBUTIONS}

All authors listed have made a substantial, direct and intellectual contribution to the work, and approved it for publication.

\section{REFERENCES}

Anthopoulos, L., Janssen, M., and Weerakkody, V. (2016). A Unified Smart City Model (USCM) for smart city conceptualization and benchmarking. Int. J. Electron.Gov. Res. 12, 77-93. doi: 10.4018/IJEGR.2016040105

Anttiroiko, A.-V. (2016). City-as-a-platform: the rise of participatory innovation platforms in finnish cities. Sustainability 8, 1-31. doi: 10.3390/su8090922

Arnkil, R., Järvensivu, A., Koski, P., and Piirainen, T. (2010). Exploring quadruple helix: outlining user-oriented innovation models. Tyo raportteja 85/2010 Working Papers. Tampere: University of Tampere, Institute for Social Research. Available online at: https://trepo.tuni.f//bitstream/handle/10024/65758/978951-44-8209-0.pdf? sequence $\$=\$ 1$ \&isAllowed $\$=\$$ y (accessed March 12, 2020).

Barns, S. (2016). Mine your data: open data, digital strategy, and entrepreneurial governance by code. Urban Geogr. 37, 554-571. doi: $10.1080 / 02723638.2016 .1139876$

Borkowska, K., and Osborne, M. (2018). Locating the fourth helix: rethinking the role of civil society in developing smart learning cities. Int. Rev. Educ. 64, 355-372. doi: 10.1007/s11159-018-9723-0

Calzada, I., and Cowie, P. 1. (2017). Beyond smart and data-driven city-regions? rethinking stakeholder-helixes strategies. Regions Magazine. 308. Available online at: https://www.researchgate.net/publication/318815983 (accessed March 12, 2020).

Carayannis, E., and Campbell, D. (2009). 'Mode 3' and 'quadruple helix': toward a 21 st century fractal innovation ecosystem. Int. J. Technol. Manag. 46, 201-234. doi: 10.1504/IJTM.2009.023374

Cavallini, S., Soldi, R., Friedl, J., and Volpe, M. (2016). Using the Quadruple Helix Approach to Accelerate the Transfer of Research and Innovation Results to Regional Growth. Available online at: https://www.researchgate.net/ publication/313251488 (accessed March 12, 2020).

Chesbrough, H. (2006). Open Innovation: The New Imperative For Creating and Profiting From Technology. Boston, MA: Harvard Business Press.

Couldry, N., and Mejias, U. (2019). The Costs of Connection: How Data is Colonizing Human Life and Appropriating it for Capitalism. Stanford, CA: Stanford University Press.

Etzkowitz, H., and Leydesdorff, L. (2000). The dynamics of innovation: from national systems and "Mode 2" to a triple helix of university-industry-government relations. Res. Policy 29, 109-123. doi: 10.1016/S0048-7333(99)00055-4

Evans, D. S., and Schmalensee, R. (2016). Matchmakers: The New Economics of Multisided Platforms. Boston, MA: Harvard Business Review Press.

Gillespie, T. (2010). The politics of 'platforms.' New Media Soc. 12, 347-364. doi: $10.1177 / 1461444809342738$

Gillespie, T. (2018). "Regulation of and by platforms," in The Sage Handbook of Social Media, eds J. Burgess, A. Marwick, and T. Poell (London: SAGE), 254-278.

Janssen, M., and Charalabidis, Y., and Krcmar, H. (2017). "Introduction to open data, information processing, and datification in government Minitrack," in Hawaii International Conference on System Sciences (Waikoloa Village, HI). doi: 10.24251/HICSS.2017.322

Kitchin, R., Cardullo, P., and Di Feliciantonio, C. (2018). "Citizenship, justice and the right to the smart city," in The Right to the Smart City, eds P. Cardullo, C. Di Feliciantonio, and R. Kitchin (Maynooth: Center for Open Science), 1-24. doi: $10.31235 /$ osf.io/b8aq5

Linders, D. (2012). From e-government to we-government: defining a typology for citizen coproduction in the age of social media. Gov. Inf. Q. 29, 446-454. doi: 10.1016/j.giq.2012.06.003

Livingstone, S. (2019). Audiences in an age of datafication: critical questions for media research. Telev. New Media 20, 170-183. doi: $10.1177 / 1527476418811118$

Mayer-Schönberger, V., and Cukier, K. (2013). Big Data: A Revolution That Will Transform How We Live, Work, and Think. Boston, MA: Houghton Mifflin Harcourt.

\section{FUNDING}

Part of this research was funded in the context of the Smart Flanders program (2017-2019), a subsidy granted to IMEC VZW by the Flemish Government.

Nieborg, D. B., and Poell, T. (2018). The platformization of cultural production: theorizing the contingent cultural commodity. New Media Soc. 20, 4275-4292. doi: $10.1177 / 1461444818769694$

O'Reilly, T. (2017). WTF?: What's the Future and Why It's Up to Us. HarperCollins Publishers. Available online at: https://www.oreilly.com/library/ view/wtf-whats-the/9780062565723/ (accessed March 12, 2020).

Parker, G., and Van Alstyne, M. (2018). Innovation, openness, and platform control. Manag. Sci. 64, 3015-3032. doi: 10.1287/mnsc.2017.2757

Plantin, J. C., and Punathambekar, A. (2019). Digital media infrastructures: pipes, platforms, politics. Media Cult. Soc. 41, 163-174. doi: 10.1177/0163443718818376

Rathbun, B. C. (2008). "Interviewing and qualitative field methods: pragmatism and practicalities," in The Oxford Handbook of Political Methodology, eds J. M. Steffensmeier and D. Collier (Oxford: Oxford University Press), 685-701.

Rochet, J.-C., and Tirole, J. (2003). Platform competition in two- sided markets. J. Eur. Econ. Assoc. 1, 990-1029. doi: 10.1162/154247603322493212

Schmidt, C. (2004). "The analysis of semi-structured interviews", in A Companion to Qualitative Research, eds U. Flick, E. von Kardoff, and I. Steinke (Londen: Sage), 253-258.

Schütz, F., Heidingsfelder, M. L., Schraudner, M. (2019). Co-shaping the future in quadruple helix innovation systems: uncovering public preferences toward participatory research and innovation. She Ji 5, 128-146. doi: 10.1016/j.sheji.2019.04.002

Schuurman, D., Baccarne, B., Marez, L., Veeckman, C., and Ballon, P. (2014). Living labs as open innovation systems for knowledge exchange: solutions for sustainable innovation development. Int. J. Bus. Innov. Res. 10, 322-340. doi: 10.1504/IJBIR.2016.074832

Sine Nomine (2018). Maximale verhuur via AirBnB in Amsterdam 30 dagen. NOS. Available online at: https://nos.nl/artikel/2211273-maximale-verhuurvia-airbnb-in-amsterdam-30-dagen.html (accessed March 12, 2020).

Srnicek, N. (2017). Platform Capitalism. Cambridge: Polity Press.

van der Graaf, S. (2018a). ComMODify! User Creativity at the Intersection of Commerce and Community. Cham: Palgrave MacMillan.

van der Graaf, S. (2018b). In waze we trust: algorithmic governance of the public sphere. Media Commun. 6, 153-162. doi: 10.17645/mac.v6i4.1710

van der Graaf, S., and Ballon, P. (2019). Navigating platform urbanism. Technol. Forecast. Soc. Change 142, 364-372. doi: 10.1016/j.techfore.2018. 07.027

van Dijck, J., Nieborg, D., and Poell, T. (2019). Reframing platform power. Internet Policy Rev. 8, 1-18. doi: 10.14763/2019.2.1414

van Dijck, J., Poell, T., and de Waal, M. (2018). The Platform Society: Public Values in a Connective World. Oxford: Oxford University Press.

von Hippel, E. (2005). Democratizing Innovation. Cambridge, MA: MIT Press.

Walravens, N. (2016). Should there be an app for that? public value creation from 'smart' mobile application initiatives for brussels and local governments ( $\mathrm{Ph} . \mathrm{D}$. Thesis). Vrije Universiteit Brussel, Brussels, Belgium.

Walravens, N., Van Compernolle, M., Waeben, J., and Colpaert, P. (2019). "Being a smart city is not the goal, but what is? a quantitative and qualitative analysis of smart city strategies in 13 cities in flanders, Belgium," in Proceedings of the IEEE CTTE \& FITCE Conference (Ghent: IEEE).

Conflict of Interest: The authors declare that the research was conducted in the absence of any commercial or financial relationships that could be construed as a potential conflict of interest.

Copyright (c) 2020 Borghys, van der Graaf, Walravens and Van Compernolle. This is an open-access article distributed under the terms of the Creative Commons Attribution License (CC BY). The use, distribution or reproduction in other forums is permitted, provided the original author(s) and the copyright owner(s) are credited and that the original publication in this journal is cited, in accordance with accepted academic practice. No use, distribution or reproduction is permitted which does not comply with these terms. 